\title{
PROYEKSI KINERJA SIMPANG EMPAT BERSINYAL TERMINAL LAMA KOTA TAKENGON SAMPAI TAHUN 2027
}

\author{
M.Noval Diara Gayo ${ }^{1)}$, Wesli $^{2)}$, Zulfhazli $^{3)}$ \\ Jurusan Teknik Sipil Universitas Malikussaleh \\ Emai: muhammadnovval@gmail.com ${ }^{l)}$,wesli@unimal.ac.id ${ }^{2}$, \\ Zulfhazli.abdullah@gmail.com ${ }^{3)}$
}

DOI: http://dx.doi.org/10.29103/tj.v7i2.137

\begin{abstract}
Abstrak
Persimpangan terminal lama kota Takengon terdiri dari empat lengan pada masing-masing lengannya memiliki pergerakan arus lalu lintas yang berbedabeda, hal ini menyebabkan titik temu pada persimpangan bergerak secara tidak beraturan sehingga dapat menyebabkan terjadinya kemacetan, tundaan dan kecelakaan lalu lintas dimasa mendatang. Proyeksi kinerja simpang empat bersinyal dilakuakan untuk mengetahui kondisi lalu lintas di tahun 2027. Tujuannya adalah untuk mengetahui besarnya kinerja simpang pada proyeksi tahun 2027. Analisis menggunakan metode (MKJI) 1997. Data terdiri dari data primer dan data sekunder, data primer terdiri dari arus lalu lintas, dimensi geometrik simpang dan pertumbuhan lalu lintas sedangkan data sekunder terdiri dari jumlah penduduk dan peta kota Takengon. Hasil pada kondisi eksisiting didapat nilai derajat kejenuhan pada pendekat SS sebesar 0,67, SU sebesar 0,69 dan KM sebesar 0,65, tundaan lalu lintas pada pendekat SS sebesar 20,2 det/smp, SU sebesar 23,6 det/smp dan KM sebesar $0,65 \mathrm{det} / \mathrm{smp}$ dengan nila tundaan rata-rata 25,35 termasuk dalam tingkat pelayaan D (kurang), arus lalu mulai memasuki arus tidak stabil serta perubahan volume lalu lintas sangat mempengaruhi besarnya kecepatan perjalanan, hasil yang didapat sesudah simpang didesain, derajat kejenuhan pada pendekat SS sebesar 0,63, SU sebesar 0,62 dan KM sebesar 0,56, tundaan lalu lintas pada pendekat SS sebesar 14,9 det/smp, SU sebesar 21,7 det/smp dan KM sebesar 25,4 det/smp dengan nilai tundaan rata-rata 20,7 termasuk dalam tingkat pelayaan $\mathrm{C}$ (sedang), arus lalu lintas masih stabil akan tetapi kecepatan dan kebebasan bergerak sudah dipengaruhi oleh besarnya volume lalu lintas sehingga pengemudi tidak dapat lagi memilih kecepatan yang diinginkan. Hal ini menunjukkan bahwa Pemerintah setempat perlu mendesain simpang tahun 2027, pemasangan lampu lalu lintas dilakukan pada saat simpang memerlukan treatment di tahun 2034.
\end{abstract}

Kata kunci : simpang bersinyai, kinerja, desain, proyeksi

\section{Pendahuluan}

Persimpangan sebagai pertemuan dari beberapa ruas jalan yang merupakan titik kritis pada jaringan jalan. Pada bagian kritis ini potensi permasalahan yang dapat terjadi digambarkan dengan banyaknya konflik arus lalu lintas sebagai akibat bertemunya beberapa arus dari berbagai arah pergerakan kendaraan pada titik yang sama.

Persimpangan terminal lama kota Takengon terdiri dari empat lengan, pada masing-masing lengan persimpangan memiliki pergerakan arus lalu lintas yang berberda-beda, seperti pergerakan arus lalu lintas dari lengan selatan (Jl. Sengeda) dan lengan barat (Jl. Terminal) persimpangan dengan kondisi satu jalur dan satu 
arah pergerakan lalu lintas sedangkan pergerakan arus lalu lintas pada lengan timur (Jl Keramat Mufakat) dan lengan utara (Jl. Sengeda) persimpangan dengan kondisi satu jalur dan dua arah pergerakan lalu lintas, hal ini menyebabkan pergerakan arus lalu lintas pada titik temu persimpangan bergerak secara tidak beraturan. Pergerakan arus lalu lintas secara tidak beraturan pada persimpangan terminal lama sudah terjadi dalam kurun waktu yang cukup lama, menurut informasi dari Dinas Perhubungan kota Takengon, sejak tahun 2003 sampai saat ini, hal ini bisa dilihat dari kondisi pengaturan lampu lalu lintas (traffic light) saat ini, yang mana lampu lalu lintas dipasang dan diatur fase sinyalnya untuk mendukung pergerakan arus lalu lintas yang tidak beraturan bagi pengguna kendaraan untuk melewati persimpangan tersebut.

Berdasarkan permasalahan yang terjadi maka penelitian ini bertujuan untuk mengetahui besarnya kinerja simpang pada kondisi eksisting, pada proyeksi tahun 2027 dan untuk mengetahui besarnya kinerja simpang memerlukan treatment

\section{Tinjauan kepustakaan}

\subsection{Prosudur Perhitungan Berdasarkan MKJI}

Variabel yang digunakan untuk menghitung kapasitas, volume, fase sinyal, tundaan dan lain-lain pada persimpangan mengacu pada rumus-rumus pada Manual Kapasitas Jalan Indonesia, 1997 dan juga rumus proyeksi.

\subsubsection{Rasio kendaraan}

Rasio kendaran belok kiri $\mathrm{P}_{\mathrm{LT}}$ dan rasio kendaraan belok kanan $\mathrm{P}_{\mathrm{RT}}$ dihitung dengan menggunakan persamaan:

$$
\begin{gathered}
P_{L T}=\frac{L T(\mathrm{smp} / \mathrm{jam})}{\operatorname{Total}(\mathrm{smp} / \mathrm{jam})} \\
P_{R T}=\frac{R T(\mathrm{smp} / \mathrm{jam})}{\operatorname{Total}(\mathrm{smp} / \mathrm{jam})}
\end{gathered}
$$

\subsubsection{Faktor penyesuaian}

Faktor penyesuaian terdiri dari beberapa bagian diantaranya seperti yang diperlihatkan dibawah ini:

1. Pengaruh ukuran kota

Faktor ini mengikuti jumlah penduduk kota seperti yang diperlihatkan pada Tabel 1.

Tabel 1 Pengaruh ukuran kota

\begin{tabular}{|c|c|c|}
\hline Jumlah Penduduk (juta) & Faktor Ukuran Kota (Fcs) & Ukuran Kota (cs) \\
\hline$>3,0$ & 1,05 & Sangat besar \\
\hline $1,0-3,0$ & 1,00 & Besar \\
\hline $0,5-1,0$ & 0,94 & Sedang \\
\hline $0,1-0,5$ & 0,83 & Kecil \\
\hline$<0,1$ & 0,82 & Sengat Kecil \\
\hline
\end{tabular}

Sumber: Direktorat Jendral Bina Bina Marga (1997) 
2. Akibat pengaruh belok kanan

$$
F_{R T}=1,0+P_{R T} x 0,6
$$

3. Akibat pengaruh belok kiri

$$
F_{L T}=1,0+P_{L T} \times 0,16
$$

\subsubsection{Arus jenuh}

Arus jenuh mempunyai apa yang disebut arus jenuh dasar seperti hanya Wabster, tapi besarnya sangat tergantung pada tipe pendekatan.

1. Tipe $\mathrm{P}$ (arus terlindung)

$$
\text { So }=600 \times W e(s m p / \text { jam })
$$

2. Tipe $\mathrm{O}$ (arus terlawan)

$$
S=\text { So } x \text { Fcs } x \text { Fsf } x \text { Fg } x \text { Fp } x \text { Frt } x \text { Flt }
$$

\subsubsection{Rasio arus dan rasio fase}

Rasio arus dapat dihitung dengan menggunakan rumus yang diperlihatkan dibawah ini:

$$
F R=\frac{Q}{S}
$$

Rasio fase sebagai rasio antara $\mathrm{FR}_{\mathrm{CR}}$ dan IFR, dapat dihitung dengan menggunakan rumus yang diperlihatkan dibawah ini:

$$
P R=\frac{F R_{C R I T}}{I F R}
$$

\subsubsection{Penentuan waktu sinyal}

Penentuan waktu sinyal untuk kendaraan dengan kendali waktu tetap dilakukan berdasarkan metoda Webster 1966 untuk meminimumkan tundaan total pada suatu simpang.

1. Waktu siklus (cycle time) adalah panjang waktu yang diperlukan dari rangkaian urutan fase lalu lintas (siklus).

$$
C_{U A}=\frac{1,5 x L T I+5}{1-\Sigma F R_{C R I T}}
$$

2. Waktu hijau (green time)

$$
g_{i}=\left(C_{U A}-L T I\right) \times P R
$$

3. Waktu siklus yang disesuaikan (c)

$$
C=\Sigma g+L T I
$$

\subsubsection{Kapasitas}

Kapasitas persimpangan didefenisikan untuk setiap bagian kakinya, kapasitas ini merupakan tingkat arus maksimum (maximum rate of flow) yang dapat melalui persimpangan pada keadaan lalu lintas awal dan keadaan jalan serta tanda-tanda lalu lintasnya. 
Menurut (Bina Marga, 1997) persamaan untuk menghitung kapasitas pada masing-masing pendekatan adalah sebagai berikut:

$$
C=S x \frac{g}{c}
$$

\subsubsection{Derajat kejenuhan}

Derajat kejenuhan adalah rasio arus terhadap kapasitas jalan. Biasanya digunakan sebagai faktor kunci dalam penentuan perilaku lalu lintas pada suatu segmen jalan dan simpang (Bina Marga, 1997).

$$
D S=\frac{Q x C}{s \times g}
$$

Perlu diperhatikan untuk analisis oprasional dan peningkatan simpang bersinyal untuk tidak melewati rasio arus $/$ kapasitas $=0,75$ selama jam puncak (Bina Marga, 1997).

\subsubsection{Perilaku lalu lintas}

Perilaku lalu lintas merupakan ukuran kuwantitatif yang menerangkan kondisi oprasional fasilitas lalu lintas seperti yang dinilai oleh pembina jalan.

1. Pajang antrian

Antrian suatu kendaraan adalah gangguan yang terjadi secara berkala akibat adanya sinyal atau lampu lalu lintas pada persimpangan (Bina Marga, 1997).

$$
N Q_{1}=0,25 \times C \times\left[(D S-1+\sqrt{(D S}-1)^{2}+\frac{8 x(D S-0,5)}{C}\right]
$$

2. Kendaraan terhenti (NS)

Waktu henti didefinisikan sebagai waktu yang dibutuhkan oleh angkutan umum untuk berhenti pada suatu titik pengamatan tertentu (Bina Marga, 1997).

$$
N S=\frac{0,9 \times N Q}{Q \times C} \times 3600
$$

3. Tundaan (delay)

Tundaan (delay) adalah waktu tempuh tambahan yang diperlukan untuk melalui simpang dibandingkan lintasan tanpa melalui suatu simpang. Tundaan lalu lintas (DT), dihitung dengan menggunakan persamaan:

$$
D T=c \times A+\frac{N Q_{1} \times 3600}{C}
$$

\subsection{Forecasting (Perkiraan)}

Perkiraan adalah suatu kegiatan yang memperkirakan apa yang akan terjadi pada masa mendatang (Wesli, 2016). Peramalan diperlukan karena perbedaan waktu antara keadaan yang akan dibutuhkannya suatu kebijakan baru. Apabila perbedaa waktu tersebut panjang, maka peran perkiraan menjadi Penentuan Forecasting tahun tersebut dapat ditentukan dengan menggunakan persamaan: 


$$
P n=P o(1+r)^{n}
$$

\section{Metode Penelitian}

Metoda yang dilakukan dalam menganalisis simpang empat bersinyal adalah sebagai berikut:

1. Indentifikasi masalah, melihat masalah yang terjadi di persimpangan melalui pengamatan secara visual terhadap kondisi dari geometrik simpangan dan juga pergerakan arus lalu lintas yang tidak beraturan

2. Persiapan, berupa studi kepustakaan mengenai hal-hal yang berkaitan dengan perencanaan persimpangan sebidang dan rumus proyeksi pertumbuhan kendaraan

3. Survei pendahuluan, melakukan pengukuran dimensi dari masing-masing lengan persimpangan, mencatat waktu siklus dan pengamatan arus lalu lintas

4. Pengumpulan data berupa data primer dan data sekunder.

5. Analisis data primer dan data sekunder mengunakan Manual Kapasitas Jalan Indonesia 1997 dan rumus proyeksi pertumbuhan kendaraan

6. Perencanaan geometrik persimpangan, mengatur gerakan arus lalu lintas menjadi.

Lokasi penelitian dilaksanakan dipersimpangan terminal lama kota Takengon, Provinsi Aceh. Pengumpulan data berupa data primer dan data skunder.

Data primer adalah data yang diperoleh atau dikumpulkan secara langsung dari sumber datanya seperti:

a. Data arus lalu lintas didapatkan dari survei di lapangan, survei dilakukan pada masing-masing lengan persimpangan

b. Data jumlah fase dan waktu lalu lintas di dapatkan dari survei di lapangan, dengan cara mencatat waktu siklus, waktu hijau, waktu merah dan waktu kuning pada lampu lalu lintas.

c. Data dimensi geometrik simpang juga di dapatkan dari hasil survei lapangan, yang mana masing-masing lengan persimpangan diukur dengan mengunakan alat ukur panjang (rol) untuk mengetahui lebar pendekatan, lebar masuk, lebar keluar, pembagian jalur, ada atau tidak adanya median serta lebar dari median itu sendiri dan jarak antara simpang.

d. Data pertumbuhan lalu lintas di dapatkan dari Polres Aceh Tengah Takengon, berupa angka pertumbuhan per setiap kendaraan dalam pertahunnya seperti angka pertumbuhan mobil penumpang, mobil barang, bus, sepeda motor dan becak.

Data sekunder adalah data yang diperoleh atau dikumpulkan dari berbagai sumber yang telah ada (peneliti sebagai tangan kedua).

a. Data jumlah penduduk kabupaten Aceh Tengah didapatkan dari (H. Mukhtaruddin, 2016), data jumlah penduduk akan di gunakan untuk faktor pengaruh ukuran kota. 
b. Peta Kota Takengon digunakan untuk mengetahui lokasi persimpanga terminal lama.

Untuk mendapatkan volume kendaraan, semua dilakukan survei dengan baik dan benar sesuai langkah-langkah yang telah diberikan. Berikut hal yang harus diperhatikan dalam survei kendaraan.

1. Waktu survei

Waktu survei pengamatan dilakukan 12 jam penuh dari jam $07.00 \mathrm{WIB}$ s/d 18.00 WIB untuk setiap hari selama 21 hari. Survei lalu lintas dilakukan pada hari senin, selasa, rabu, kamis, jum'at, sabtu dan minggu. Perhitungan dilakukan per 15 menit.

2. Tipe kendaraan

Tipe kendaraan yang diamati dikelompokkan dalam empat jenis, yaitu:

a. Kendaraan ringan (light Vehicel / LV)

b. Kendaraan berat (heavy vehicle / HV)

c. Sepeda motor (motor cycle / MC)

\section{Hasil dan Pembahasan}

\subsection{Hasil}

Nilai yang digunakan untuk kondisi eksisting simpang terminal lama berdasarkan tabel lalu lintas harian rata-rata, diambil volume lalu lintas rata-rata tertinggi sebagai perwakilan dari jam puncak rata-rata yaitu terjadi pada rata-rata jam puncak hari rabu pukul 17:00 - 18:00, Pertumbuhan kendaraan yang diproyeksikan untuk tahun 2027 berdasarkan nilai kondisi eksisting simpang terminal lama

Persimpangan terminal lama benar-benar bermasalah terjadi pada tahun 2034 dengan besar kapasitas simpang pada pendekat sengeda selatan 1373 smp/jam, sengeda utara $743 \mathrm{smp} / \mathrm{jam}$ dan keramat mufakat $177 \mathrm{smp} / \mathrm{jam}$, seperti yang diperlihatkan pada Tabel 2

Tabel 2 Arus lalu lintas

\begin{tabular}{|c|c|c|c|c|c|c|c|c|}
\hline \multirow{2}{*}{ Pendekat } & \multirow{2}{*}{ Waktu } & \multirow{2}{*}{ Pergerakan } & \multicolumn{2}{|c|}{ Volume } & \multicolumn{2}{|c|}{$\begin{array}{c}\text { Volume Tahun } \\
2027\end{array}$} & \multicolumn{2}{|c|}{$\begin{array}{c}\text { Volume Tahun } \\
2034\end{array}$} \\
\hline & & & $\begin{array}{l}\text { Kend/ } \\
\text { jam }\end{array}$ & $\begin{array}{c}\text { Smp/ } \\
\text { jam }\end{array}$ & $\begin{array}{c}\text { Kend/ } \\
\text { jam }\end{array}$ & $\begin{array}{c}\text { Smp/ } \\
\text { jam }\end{array}$ & $\begin{array}{c}\text { Kend/ } \\
\text { jam }\end{array}$ & $\begin{array}{c}\text { Smp/ } \\
\text { jam }\end{array}$ \\
\hline \multirow{4}{*}{ SS } & \multirow{4}{*}{$\begin{array}{c}17: 00 \\
- \\
18: 00\end{array}$} & ST & 1041,6 & 419,6 & 1342 & 563 & 1582 & 684 \\
\hline & & RT & 121 & 51,2 & 155 & 68 & 183 & 82 \\
\hline & & LT & 964,3 & 373,2 & 1239 & 500 & 1459 & 606 \\
\hline & & Total & 2126,9 & 844 & 2736 & 1131 & 3224 & 1373 \\
\hline \multirow{3}{*}{ SU } & \multirow{3}{*}{$\begin{array}{c}17: 00 \\
- \\
18: 00\end{array}$} & $\mathrm{RT}$ & 1078 & 407 & 1382 & 543 & 1625 & 657 \\
\hline & & LT & 108 & 52 & 138 & 70 & 165 & 86 \\
\hline & & Total & 1186 & 460 & 1520 & 612 & 1790 & 743 \\
\hline \multirow{3}{*}{$\mathrm{KM}$} & \multirow{3}{*}{$\begin{array}{c}17: 00 \\
- \\
18: 00\end{array}$} & ST & 149,4 & 55,3 & 189 & 72 & 222 & 86 \\
\hline & & RT & 110,7 & 54,1 & 143 & 73 & 172 & 91 \\
\hline & & Total & 260,1 & 109,4 & 332 & 144 & 394 & 177 \\
\hline
\end{tabular}




\subsection{Pembahasan}

Berdasarkan hasil pengamatan dilapangan pada kondisi eksisting arus lalu lintas yang melewati persimpangan berjumlah 3573 kendaraan, setelah dikonversikan menjadi SMP berjumlah $1414 \mathrm{smp} / \mathrm{jam}$. Kapasitas simpang pada kondisi eksisting pendekat sengeda selatan $1521 \mathrm{smp} / \mathrm{jam}$, pendekat sengeda utara $790 \mathrm{smp} / \mathrm{jam}$ dan pendekat keramat mufakat $197 \mathrm{smp} / \mathrm{jam}$.

Derajat kejenuhan pada kondisi eksisting pendekat sengeda selatan 0,56 $\mathrm{smp} / \mathrm{jam}$, pendekat sengeda utara $0,58 \mathrm{smp} / \mathrm{jam}$ dan pendekat keramat mufakat $0,56 \mathrm{smp} / \mathrm{jam}$ untuk nilai derajat kejenuhan pada ke tiga pendekat $\leq 0,75$, hal ini menunjukkan arus lalu lintas yang bergerak pada ke tiga pendekat masih dalam keadaan stabil.

Perilaku lalu lintas dilihat dari tiga fakto utama yang mempengaruhinya, (1) panjang antrian (QL) pada pendekat sengeda selatan $320 \mathrm{~m}$, pendekat sengeda utara $34 \mathrm{~m}$ dan pendekat keramat mufakat $40 \mathrm{~m}$. Terjadinya antrian yang sangat panjang pada pendekat sengeda selatan disebabkan nila $\mathrm{W}_{\text {masuk }}$ pada pendekat tersebut tidak ada sehingga hasil penjumlahan panjang antrian menggunakan rumus 19 didapatkan hasil 320 m, meskipun sebenarnya dalam keadaan real di lapangan tidak terjadi panjang antrian yang demikian. (2) kendaraan terhenti (Nsv) pada pendekat sengeda selatan $646 \mathrm{smp} / \mathrm{jam}$, pendekat sengeda utara 379 smp/jam dan pendekat keramat mufakat $105 \mathrm{smp} / \mathrm{jam}$, penjumlahan kendaraan terhenti dari ke tiga pendekat adalah $1131 \mathrm{smp} / \mathrm{jam}$. (3) tundaan lalu lintas pada pendekat sengeda selatan 12,5 det/smp, pendekat sengeda utara 14,8 det/smp dan pendekat keramat mufakat $20 \mathrm{det} / \mathrm{smp}$.

Dengan nilai tundaan rata-rata $19,7 \mathrm{det} / \mathrm{smp}$ termasuk dalam tingkat pelayanan C (sedang). Arus lalu lintas masih stabil, kecepatan perjalanan dan kebebasan bergerak sudah dipengaruhi oleh besar volume lalu lintas sehingga pengemudi tidak dapat lagi memilih kecepatan yang diinginkan.

Setelah dilakukan proyeksi pada semua jenis kendaraan yang melewati simpang, ditujukan untuk tahun 2027 dengan arus lalu lintas yang melewati simpang berjumlah 4581 kendaraan, setelah dikonversikan menjadi SMP berjumlah $1887 \mathrm{smp} / \mathrm{jam}$, terjadi peningkatan jumlah kendaraan setelah dilakukan poyeksi dari tahun 2017 ke tahun 2027.

Kapasitas simpang pada tahun 2027 pada pendekat sengeda selatan 1700 smp/jam, pendekat sengeda utara $893 \mathrm{smp} / \mathrm{jam}$ dan pendekat keramat mufakat 223 smp/jam. Derajat kejenuhan pada tahun 2027 pada pendekat sengeda selatan 0,67 $\mathrm{smp} / \mathrm{jam}$, pendekat sengeda utara $0,69 \mathrm{smp} / \mathrm{jam}$ dan pendekat keramat mufakat $0,65 \mathrm{smp} / \mathrm{jam}$.

Peningkatan jumlah kendaraan terjadi setelah dilakukan proyeksi kendaraan, begitu juga dengan nilai derajat kejenuhan yang meningkat, akan tetapi peningkatan nilai derajat kejenuhan di tahun 2027 tidak melewati $\leq 0,75$ pada ke tiga pendekat simpang, hal ini menunjukkan simpang tersebut masih dalam keadaan stabil.

Perilaku lalu lintas pada tahun 2027 dilihat dari tiga fakto utama yang mempengaruhinya, (1) panjang antrian (QL) pada pendekat sengeda selatan 440 $\mathrm{m}$, pendekat sengeda utara $48 \mathrm{~m}$ dan pendekat keramat mufakat $53 \mathrm{~m}$. Terjadinya antrian yang sangat panjang pada pendekat sengeda selatan disebabkan nila 
$\mathrm{W}_{\text {masuk }}$ pada pendekat tersebut tidak ada sehingga hasil penjumlahan panjang antrian menggunakan rumus 19 didapatkan hasil $440 \mathrm{~m}$, meskipun sebenarnya dalam keadaan real di lapangan tidak terjadi panjang antrian yang demikian. (2) kendaraan terhenti (Nsv) pada pendekat sengeda selatan $909 \mathrm{smp} / \mathrm{jam}$, pendekat sengeda utara $531 \mathrm{smp} / \mathrm{jam}$ dan pendekat keramat mufakat $149 \mathrm{smp} / \mathrm{jam}$, penjumlahan kendaraan terhenti dari ke tiga pendekat adalah $1581 \mathrm{smp} / \mathrm{jam}$. (3) tundaan lalu lintas pada pendekat sengeda selatan 20,2 det/smp, pendekat sengeda utara 23,6 det/smp dan pendekat keramat mufakat 32,2 det/smp. Dengan nilai tundaan rata-rata $25,35 \mathrm{det} / \mathrm{smp}$ termasuk dalam tingkat pelayanan D (kurang) di tahun 2027.

Kinerja simpang sudah memerlukan treatment terjadi pada tahun 2034 dengan arus lalu lintas yang melewati simpang berjumlah 5408 kendaraan, setelah dikonversikan menjadi satuan mobil penumpang berjumlah $2293 \mathrm{smp} / \mathrm{jam}$, terjadi peningkatan jumlah kendaraan dari tahun-tahun sebelumnya, peningkatan ini menjadi faktor penyebab bermasalahnya kinerja simpang tahun 2034 .

Kapasitas simpang pada tahun 2034 pada pendekat sengeda selatan 1760 smp/jam, pendekat sengeda utara 939 smp/jam dan pendekat keramat mufakat 223 smp/jam. Derajat kejenuhan pada tahun 2034 pada pendekat sengeda selatan 0,78 smp/jam, pendekat sengeda utara $0,79 \mathrm{smp} / \mathrm{jam}$ dan pendekat keramat mufakat 0,79 smp/jam. Peningkatan jumlah kendaraan terjadi setelah dilakukan proyeksi kendaraan, begitu juga dengan nilai derajat kejenuhan yang meningkat, peningkatan nilai derajat kejenuhan di tahun 2034 melewati $\leq 0,75$ pada ke tiga pendekat simpang, hal ini menunjukkan simpang tersebut dalam keadaan tidak stabil.

Perilaku lalu lintas pada tahun 2034 dilihat dari tiga fakto utama yang mempengaruhinya, (1) panjang antrian (QL) pada pendekat sengeda selatan 560 $\mathrm{m}$, pendekat sengeda utara $62 \mathrm{~m}$ dan keramat mufakat $60 \mathrm{~m}$. Terjadinya antrian yang sangat panjang pada pendekat sengeda selatan disebabkan nila $\mathrm{W}_{\text {masuk }}$ pada pendekat sengeda selatan tidak ada sehingga hasil penjumlahan panjang antrian menggunakan rumus 19 didapatkan hasil $560 \mathrm{~m}$, meskipun sebenarnya dalam keadaan real di lapangan tidak terjadi panjang antrian yang demikian. (2) kendaraan terhenti (Nsv) pada pendekat sengeda selatan $1177 \mathrm{smp} / \mathrm{jam}$, pendekat sengeda utara $702 \mathrm{smp} / \mathrm{jam}$ dan pendekat keramat mufakat $238 \mathrm{smp} / \mathrm{jam}$, penjumlahan kendaraan terhenti dari ke tiga pendekat adalah $2117 \mathrm{smp} / \mathrm{jam}$. (3) tundaan lalu lintas pada pendekat sengeda selatan 19,5 det/smp, pendekat sengeda utara 23,8 det/smp dan pendekat keramat mufakat 43,5 det/smp.

Dengan nilai tundaan rata-rata 28,92 det/smp termasuk dalam tingkat pelayanan D (kurang), dimana arus lalu lintas mulai memasuki arus tidak stabil, perubahan volume lalu lintas sangat mempengaruhi besarnya kecepatan perjalanan.

Waktu siklus tahun 2034 pada simpang 68 detik dengan waktu hijau 53 detik dan waktu hilang 14 detik, waktu hijau pada masing-masing pendekat terdiri dari 24 detik sengeda selatan, 19 detik sengeda utara dan 10 detik keramat mufakat. Hijau yang lebih pendek dari 10 detik harus dihindari, karena dapat mengakibatkan pelanggaran lampu merah yang berlebihan dan kesulitan bagi pejalan kaki untuk menyebrang jalan (Bina Marga, 1997), tabel komparasi eksisting tahun 2027 dan 2034 diperlihatkan pada Tabel 3. 
Tabel 3 Komparasi eksisting tahun 2027 dan 2034

\begin{tabular}{|c|c|c|c|c|c|c|c|c|c|c|}
\hline \multirow{2}{*}{ INDIKATOR } & \multirow{2}{*}{ SYARAT } & \multicolumn{3}{|c|}{2017} & \multicolumn{3}{|c|}{2027} & \multicolumn{3}{|c|}{2034} \\
\hline & & SS & SU & KM & SS & SU & KM & SS & SU & KM \\
\hline Kapasitas (smp/jam) & 1650 & 1521 & 790 & 197 & 1700 & 839 & 223 & 1760 & 939 & 223 \\
\hline Tundaan (det/smp) & 25 & 16,3 & 19,1 & 23,9 & 20,2 & 23,6 & 32,3 & 19,5 & 23,8 & 43,5 \\
\hline Derajat kejenuhan & 0,75 & 0,56 & 0,58 & 0,56 & 0,67 & 0,69 & 0,65 & 0,78 & 0,79 & 0,81 \\
\hline $\begin{array}{c}\text { Kecepatan rencana } \\
(\mathrm{km} / \mathrm{jam})\end{array}$ & $40-80$ & $50-80$ & $50-80$ & $60-80$ & - & - & - & - & - & - \\
\hline Waktu hijau (detik) & 10 & 13 & 10 & 5 & 18 & 14 & 7 & 24 & 19 & 10 \\
\hline Waktu siklus (detik) & $50-100$ & & 42 detil & & & 52 deti & & & 8 deti & \\
\hline
\end{tabular}

\section{$5 \quad$ Kesimpulan dan Saran}

\subsection{Kesimpulan}

Berdasarkan hasil analisis yang telah dilakukan pada bab sebelumnya, maka dapat ditarik kesimpulan sebagai berikut: Kinerja simpang terminal lama tahun 2017 dengan kapasitas simpang pada ke tiga pendekat tidak melebihi kapasitas yang disyaratkan. Tundaan lalu lintas pada kondisi eksisting pada ke tiga pendekat termasuk dalam tingkat pelayanan C. Derajat kejenuhan pada kondisi eksisting termasuk dalam tingkat pelayanan B. Kecepatan kendaraan yang melewati simpang tidak melebihi kecepatan rencana yang disyaratkan. Pemasangan lampu lalu lintas pada simpang pada kondisi eksisting masih tidak perlu dilakukan.

Kinerja simpang terminal lama pada tahun 2027 dengan kapasitas simpang pada pendekat sengeda utara dan keramat mufakat tidak melebihi kapasitas yang disyaratkan sedangkan pada pendekat sengeda selatan besar kapasitas sudah melebihi yang disyaratkan. Tundaan lalu lintas pada pendekat sengeda selatan dan sengeda utara termasuk dalam tingkat pelayanan $\mathrm{C}$ sedangkan pada pendekat keramat mufakat termasuk dalam tingkat pelayanan D. Tundaan lalu lintas ratarata simpang pada termasuk dalam tingkat pelayanan D melebihi tundaan simpang yang disyaratkan. Setelah dilakukan desain persimpangan tundaan rata-rata simpang termasuk dalam tingkat pelayanan C. Derajat kejenuhan pada ke tiga pendekat termasuk dalam tingkat pelayanan B tidak melebihi nilai derajat kejenuhan yang disyaratkan. Setelah dilakukan desain persimpangan nilai derajat kejenuhan pada ketiga pendekat mengalami penurunan nilai akan tetapi masih termasuk dalam tingkat pelayanan yang sama.

Kinerja simpang terminal lama sudah memerlukan treatment pada tahun 2034 dengan besar kapasitas pada pendekat sengeda selatan melebihi yang disyaratkan sedangkan pada pendekat sengeda utara dan keramat mufakat besar kapasitas tidak melebihi yang disyaratkan. Tundaan pada pendekat sengeda utara dan sengeda selatan termasuk dalam tingkat pelayanan $\mathrm{C}$ sedangkan pada pendekat keramat mufakat termasuk dalam tingkat pelayana $\mathrm{E}$ (Buruk), dengan nilai tundaan rata-rata simpang termasuk dalam tingkat pelayana D (Kurang) melewati tundaan simpang yang disyaratkan. Derajat kejenuhan pada pendekat sengeda utara dan sengeda selatan termasuk dalam tingkat pelayanan $C$, sedangkan pada pendekat keramat mufakat termasuk dalam tingkat pelayanan D (Kurang). Derajat kejenuhan pada ketiga pendekat melebihi nila yang disyaratkan. Pemasangan lampu lalu lintas pada kondisi eksisting tahun 2034 sangat layak untuk dilakukan melihat nilai derajat kejenuhan pada ketigan pendekat melebihi 
nilai yang disyaratkan dan tundaan rata-rata simpang termasuk dalam tingkat pelayanan D (Kurang).

\subsection{Saran}

Berdasarkan dari hasil penelitian dan kesimpulan diatas dapat diberikan saran-saran sebagai rekomendasi antara lain: Kepada pemerintah setempat disarankan untuk mengubah pergerakan arus lalu lintas yang tidak beraturan menjadi teratur dan pemasangan lampu lalu lintas pada kondisi eksisting simpang masih belum perlu dilakukan Juga disarankan untuk tidak memasang lampu lalu lintas pada kondisi eksisting tahun 2027 setelah dilakukan desain simpang. Selain itu disarankan untuk memasang lampu lalu lintas pada tahun 2034 dilihat dari nilai derajat kejenuhan melebihi nilai yang disyaratkan 0,75 , tundaan rata-rata simpang termasuk dalam tingkat pelayana D (Kurang).

\section{Daftar Kepustakaan}

Bina Marga, D. J. (1997). Manual Kapasitas Jalan Indonesia. Direktorat Jenderal Bina Marga Indonesia Departemen Pekerjaan Umum, Jakarta.

H. Mukhtaruddin, S. (2016). Aceh Tengah Dalam Angka. BPS Kabupaten Aceh Tengah.

Wesli, S. J. A. (2016). Kajian Kebutuhan Lampu Lalu Lintas Pada Simpang 6. Universitas Malikussaleh, Aceh Utara. 